\title{
MEIOS DE CULTURA E REGULADORES DE CRESCIMENTO NA MULTIPLICAÇÃO IN VITRO DE AMOREIRA-PRETA
}

\section{CULTURE MEDIUM AND GROWTH REGULATORS IN VITRO BLACKBERRY MICROPROPAGATION}

\author{
Fabíola VILLA ${ }^{1}$ \\ Moacir PASQUAL ${ }^{2}$ \\ Aline das Graças SOUZA ${ }^{3}$ \\ Ximena Maira de Souza VILELA ${ }^{3}$
}

\section{RESUMO}

A micropropagação da amoreira-preta pode gerar plantas livres de vírus e em curto espaço de tempo. Com o objetivo de aprimorar técnicas de propagação in vitro de amoreira-preta, testaram-se diferentes meios de cultivo e concentrações de 6-belzilaminopurina (BAP) e ácido indolbutírico (AIB). O primeiro experimento constou da cv. Brazos inoculada em 3 diferentes meios, combinados com cinco concentrações de BAP. O segundo experimento constou da cv. Tupy inoculada em 4 meios de cultivo, combinados com cinco concentrações de AIB. O pH do meio foi ajustado para 5,8 antes da adição de $6 \mathrm{~g}$ $\mathrm{cm}^{-3}$ de ágar e da autoclavagem a $121^{\circ} \mathrm{C}$ e $1 \mathrm{~atm}$ por $20 \mathrm{~min}$. Após a inoculação, os explantes foram mantidos por 70 dias, em sala de crescimento a $25 \pm 1{ }^{\circ} \mathrm{C}$, irradiância de $35 \mu \mathrm{mol} \mathrm{m} \mathrm{m}^{-2} \mathrm{~s}^{-1}$ e fotoperíodo de $16 \mathrm{~h}$. Os experimentos foram inteiramente casualisados, utilizando-se três explantes por repetição e 12 brotações por tratamento. Verificou-se maior número de brotos da cv. Brazos em meio de cultura MS. Comprimento e número de raízes dessa mesma cultivar foram estimulados em meio Roubelakis e MS adicionados de $0,5 \mathrm{mg} \mathrm{dm}^{-3}$ de BAP. Foi observada a formação do sistema radicular das brotações em todos os meios empregados, porém melhores resultados de 'Tupy', na ausência de AlB deu-se nos meios Knudson, NN e MS.

Palavras-chave: Rubus spp.; cultura de tecidos; BAP; AIB.

\section{ABSTRACT}

The micropropagation of blackberry can generate virus-plants free and in a short space of time. Aiming to improve in vitro propagation techniques of blackberry, were tested different culture media and 6-belzilaminopurin (BAP) concentrations and indolbutiric acid (IBA). The first experiment consisted cv. 'Brazos' inoculated in 3 different culture medium, combined with five BAP concentrations. As the second experiment consisted cv. Tupy inoculated in 4 culture medium, combined with five IBA concentrations. The $\mathrm{pH}$ of culture medium was adjusted for 5.8 before the addition of $6 \mathrm{~g} \mathrm{~cm}^{-3}$ agar and the sterilization of $121^{\circ} \mathrm{C}$ and $1 \mathrm{~atm}$ for $20 \mathrm{~min}$. After the inoculation, the explants had been kept per 70 days, in a growth room with $25 \pm 1^{\circ} \mathrm{C}$, irradiance of $35 \mathrm{mmol} \mathrm{m} \mathrm{m}^{-2} \mathrm{~s}^{-1}$ and photoperiod of $16 \mathrm{~h}$. The experiments entirely casualizated, using three explants per repetition and 12 buds per treatment. There were verified bigger number of 'Brazos' buds in culture medium MS. Length and number of roots of $\mathrm{cv}$. Brazos had been stimulated in culture medium Roubelakis and MS added $0,5 \mathrm{mg} \mathrm{dm}^{-3}$ of BAP. The formation of radicular system of this cv. was observed of buds in all culture medium studied, however better resulted of $\mathrm{cV}$ Tupy, was observed on the absence of IBA for the culture medium Knudson, NN and MS.

Key-words: Rubus spp.; tissue culture; BAP; IBA.

\footnotetext{
${ }^{1}$ Pós-doutoranda em Fitotecnia, Empresa de Pesquisa Agropecuária de Minas Gerais (EPAMIG) / Fundação de Amparo à Pesquisa do Estado de Minas Gerais (FAPEMIG), Bairro Vargedo, Maria da Fé, Minas Gerais, Brasil. E-mail: fvilla2003@libero.it_Autor para corresondência ${ }^{2}$ Professor Titular, D.Sc., Departamento de Agricultura (DAG), Universidade Federal de Lavras (UFLA). Caixa Postal 37, 37200-000, Lavras, Minas Gerais, Brasil. E-mail: mpasqual@ufla.br

${ }^{3}$ Mestranda em Fitotecnia, Departamento de Agricultura (DAG), Universidade Federal de Lavras (UFLA), Lavras, Minas Gerais, Brasil. E-mail: alinedasgracas@yahoo.com.br.
} 
VILLA, F. et al. Meio de cultura e reguladores...

\section{INTRODUÇÃO}

No Brasil, a amoreira-preta vem sendo cultivada por pequenos produtores do Rio Grande do Sul (principal produtor brasileiro), Santa Catarina e Paraná, objetivando a exportação dos frutos. No Rio Grande do Sul, as maiores produções encontram-se nos municípios de Feliz e Vacaria, onde a cultivar Tupy responde por $70 \%$ da área cultivada, com produção a partir da terceira dezena de novembro (Antunes, 2002). Em São Paulo a produção concentra-se na região de Jundiaí e em Minas Gerais, no Planalto de Poços de Caldas (Antunes et al., 2000) e Zona da Mata (Barbacena).

Atualmente, além da propagação tradicional, a micropropagação da amoreira-preta é considerada uma outra alternativa viável, com o intuito de se obter plantas livres de vírus, geneticamente uniformes e em curto espaço de tempo (Leitzke et al., 2009).

Um dos fatores importantes para o sucesso do sistema de micropropagação é a conjugação de fatores nutritivos, ambientais e endógenos. No caso específico dos fatores ambientais, procura-se estudar os componentes do meio de cultura. Neste caso, diversas formulações de meios básicos têm sido utilizadas em frutíferas. Embora não exista uma formulação padrão, o meio $M S$ e suas modificações têm apresentado resultados satisfatórios para diversas espécies (George \& Sherrington, 1984). Entretanto, com espécies lenhosas, o meio MS não se mostrou satisfatório em alguns casos (Grattapaglia \& Machado, 2004). Outras formulações como, por exemplo, o meio NN e Knudson, têm sido descritas e utilizadas como alternativas ao MS.

$O$ crescimento e a morfogênese in vitro são fatores regulados pela interação e balanço dos reguladores de crescimento existentes no meio de cultura, principalmente auxinas e citocininas (George \& Sherrington, 1984). As citocininas são utilizadas para quebrar a dominância apical dos brotos, e aumentar a taxa de multiplicação (Grimaldi et al., 2008).

As auxinas, apesar de não promoverem a proliferação de brotações axilares, podem incrementar o crescimento da cultura (Grimaldi et al., 2008). Dentre os reguladores de crescimento comumente usadas no cultivo in vitro da amoreirapreta estão a 6-benzilaminopurina (BAP) e o ácido indolbutírico (AIB) (Erig et al., 2002; Villa et al., 2006; Villa et al., 2008).

O presente trabalho objetivou avaliar o efeito das concentrações de ácido indolbutírico (AIB) e 6benzilaminopurina (BAP) adicionados à diversos meios de cultura na multiplicação in vitro de amoreira-preta cultivares Tupy e Brazos.

\section{MATERIAL E MÉTODOS}

Segmentos nodais de amoreira-preta (Rubus sp.), cultivares Tupy e Brazos, com cerca de $2 \mathrm{~cm}$, foram excisados de brotações pré-estabelecidas in vitro. Os explantes foram inoculados em tubo de ensaio contendo $15 \mathrm{~cm}^{3}$ de diversos meios de cultivo.

O primeiro experimento constou da cV. Brazos inoculada em 3 diferentes meios: 1) MS (Murashige \& Skoog, 1962), 2) Knudson (1946) e 3) Roubelakis (Roubelakis-Angelakis \& Zivanovitc, 1991), combinados com cinco concentrações de $\operatorname{BAP}\left(0 ; 0,5 ; 1,0 ; 2,0\right.$ e $\left.4,0 \mathrm{mg} \mathrm{dm}^{-3}\right)$.

O segundo experimento constou da cv. Tupy inoculada em 4 meios de cultivo: 1) MS (Murashige E\&Skoog, 1962), 2) Knudson (1946), 3) Roubelakis (Roubelakis-Angelakis \& Zivanovitc, 1991) e 4) NN (Nitsch \& Nitsch, 1969), combinados com cinco concentrações de AIB (0; 0,125; 0,25; 0,5 e 1,0 mg $\mathrm{dm}^{-3}$ ). $\mathrm{O} \mathrm{pH}$ dos meios foram ajustados para 5,8 antes da autoclavagem e solidificados com $6 \mathrm{~g} \mathrm{dm}^{-3}$ de ágar.

Posteriormente foram transferidos para sala de crescimento a $25 \pm 1{ }^{\circ} \mathrm{C}$, irradiância de $35 \mu \mathrm{mol}$ $\mathrm{m}^{-2} \mathrm{~s}^{-1}$ fornecida por tubos fluorescentes de $20 \mathrm{~W}$ e fotoperíodo de $16 \mathrm{~h}$, permanecendo nestas condições por 70 dias. $\mathrm{O}$ delineamento experimental foi inteiramente casualisado com 4 repetições constituídas e 12 plantas tratamento ${ }^{-1}$. As variáveis analisadas foram comprimento da parte aérea e das raízes (dados transformados -

$$
\sqrt{x+1}
$$

), biomassa da parte aérea, número de brotos (dados transformados $-\sqrt{x+1}$ ) e massa fresca de calos. Os resultados foram submetidos à análise de variância (Ferreira, 2000), sendo utilizado regressão polinomial para concentrações de BAP e AIB e teste de Scott-Knott para os tipos de meios de cultivo.

\section{RESULTADOS E DISCUSSÃO}

\section{Experimento 1}

Os dados obtidos no experimento 1 revelaram que houve interação significativa para todos os parâmetros estudados, exceto para número de brotos e biomassa da parte aérea (Tabela 1). Nas Tabelas 2 e 3 observa-se interação para os diferentes meios de cultivo empregados na micropropagação de amoreira-preta cv. Brazos. 
VILLA, F. et al. Meio de cultura e reguladores...

TABELA 1 - Análise de variância para número de folhas (NF), número de brotos (NB), biomassa da parte aérea (BPA), massa fresca de calos (BCA), comprimento da parte aérea (CPA), número de raízes (NR) e comprimento de raízes (CR) de amoreira-preta cv. Brazos micropropagada. UFLA, Lavras, MG, 2008.

\begin{tabular}{lcccccccc}
\hline & \multicolumn{1}{c}{ Quadrados médios } \\
\hline & GL & NF & NB & BPA & BCA & CPA & NR & CR \\
\hline BAP & 4 & $2,839^{*}$ & $11,187^{*}$ & $0,011^{\text {n.s. }}$ & $0,053^{*}$ & $1,161^{*}$ & $0,149^{\text {n.s. }}$ & $0,063^{\text {n.s. }}$ \\
MC & 2 & $1,331^{*}$ & $16,432^{*}$ & $0,468^{*}$ & $0,106^{*}$ & $5,015^{*}$ & $1,849^{*}$ & $2,251^{*}$ \\
BAP x MC & 8 & $0,891^{*}$ & $0,456^{\text {n.s. }}$ & $0,004^{\text {n.s. }}$ & $0,022^{*}$ & $4,328^{*}$ & $0,229^{*}$ & $0,300^{*}$ \\
Resíduo & 42 & 0,251 & 0,347 & 0,005 & $0,002^{*}$ & 0,422 & 0,066 & 0,066 \\
CV (\%) & & 13,58 & 22,63 & 7,97 & 5,12 & 23,37 & 18,51 & 18,43 \\
\hline
\end{tabular}

* Significativo a $5 \%$ de probabilidade pelo teste $\mathrm{F}$, n.s. $=$ não-significativo, GL = graus de liberdade, BAP = 6benzilaminopurina, $\mathrm{MC}=$ meios de cultura, $\mathrm{CV}=$ coeficiente de variação.

TABELA 2 - Diferentes meios de cultura e concentrações de BAP (6-benzilaminopurina) na micropropagação de amoreira-preta cv. Brazos. UFLA, Lavras, MG, 2008.

\begin{tabular}{|c|c|c|c|c|c|c|}
\hline & & \multicolumn{5}{|c|}{$\operatorname{BAP}\left(\mathrm{mg} \mathrm{dm}^{-3}\right)$} \\
\hline & $\begin{array}{c}\text { Tipos de meio de } \\
\text { cultura }\end{array}$ & 0 & 0,5 & 1,0 & 2,0 & 4,0 \\
\hline \multirow{3}{*}{ NF } & Knudson & 0 & 0 & 0 & $4,63 a^{*}$ & $2,48 b$ \\
\hline & MS & 0 & 0 & 0 & $4,37 \mathrm{a}$ & 3,93 a \\
\hline & Roubelakis & 0 & 0 & 0 & $3,69 \mathrm{~b}$ & $3,39 \mathrm{a}$ \\
\hline \multirow{3}{*}{ BCA } & Knudson & 0 & $0,76 \mathrm{~b}$ & $0,80 \mathrm{~b}$ & $0,77 \mathrm{c}$ & $0,71 \mathrm{c}$ \\
\hline & MS & 0 & $0,78 \mathrm{~b}$ & $0,85 \mathrm{~b}$ & $0,97 \mathrm{a}$ & $1,03 a$ \\
\hline & Roubelakis & 0 & $0,88 a$ & $0,94 \mathrm{a}$ & $0,88 \mathrm{~b}$ & $0,93 \mathrm{~b}$ \\
\hline \multirow{3}{*}{ CPA } & Knudson & $4,38 \mathrm{a}$ & $1,74 \mathrm{~b}$ & $1,28 \mathrm{~b}$ & $2,00 \mathrm{~b}$ & $1,71 \mathrm{~b}$ \\
\hline & MS & $1,88 \mathrm{c}$ & 3,67 a & $3,79 a$ & $3,29 a$ & $3,31 \mathrm{a}$ \\
\hline & Roubelakis & $3,31 \mathrm{~b}$ & $3,38 a$ & $3,38 a$ & $2,50 \mathrm{~b}$ & $2,11 \mathrm{~b}$ \\
\hline \multirow{3}{*}{ NR } & Knudson & 0 & $0,93 \mathrm{~b}$ & $0,71 \mathrm{~b}$ & $0,97 b$ & $0,93 \mathrm{~b}$ \\
\hline & MS & 0 & $1,68 \mathrm{a}$ & $1,52 \mathrm{a}$ & $1,66 \mathrm{a}$ & $1,55 \mathrm{a}$ \\
\hline & Roubelakis & 0 & $1,66 a$ & $1,52 \mathrm{a}$ & $1,47 \mathrm{a}$ & $1,56 \mathrm{a}$ \\
\hline \multirow{3}{*}{ CR } & Knudson & 0 & $0,92 b$ & $0,71 \mathrm{~b}$ & $0,97 b$ & $0,84 \mathrm{~b}$ \\
\hline & MS & 0 & $1,60 \mathrm{a}$ & $1,62 \mathrm{a}$ & $1,58 \mathrm{a}$ & $1,57 \mathrm{a}$ \\
\hline & Roubelakis & 0 & $1,80 \mathrm{a}$ & $1,78 \mathrm{a}$ & $1,65 a$ & $1,45 \mathrm{a}$ \\
\hline \multicolumn{7}{|c|}{$\begin{array}{l}\text { *Médias seguidas por letras distintas na coluna diferem entre si a } 5 \% \text { de probabilidade, pelo teste de Scott-Knott. NF = } \\
\text { número de folhas, } \mathrm{BCA}=\text { biomassa de calos, } \mathrm{CPA}=\text { comprimento da parte aérea, NR = número de raízes, CR }= \\
\text { comprimento de raízes. }\end{array}$} \\
\hline \multicolumn{7}{|c|}{$\begin{array}{c}\text { TABELA } 3 \text { - Número de brotos (NB) e biomassa da parte aérea (BPA) de amoreira-preta cv. Brazc } \\
\text { micropropagada, em diferentes meio de cultura. UFLA, Lavras, MG, } 2008 .\end{array}$} \\
\hline \multicolumn{2}{|c|}{ Tipos de meios de cultura } & \multicolumn{2}{|r|}{ NB } & \multicolumn{3}{|c|}{ BPA } \\
\hline \multicolumn{2}{|r|}{ Knudson } & \multicolumn{2}{|r|}{$1,93 b^{*}$} & \multicolumn{3}{|c|}{$0,76 \mathrm{~b}$} \\
\hline \multicolumn{2}{|r|}{ MS } & \multicolumn{3}{|c|}{$3,63 a$} & \multicolumn{2}{|c|}{$1,04 a$} \\
\hline \multicolumn{2}{|r|}{ Roubelakis } & & $2,24 \mathrm{~b}$ & & \multicolumn{2}{|c|}{$0,79 \mathrm{~b}$} \\
\hline
\end{tabular}

*Médias seguidas por letras distintas na coluna diferem entre si a 5\% de probabilidade, pelo teste de Scott-Knott. 
VILLA, F. et al. Meio de cultura e reguladores...

O número de folhas foi estimulado pelo tipo de meios de cultura e 2 e $4 \mathrm{mg} \mathrm{dm}^{-3}$ de BAP, observando a interação entre esses dois fatores (Figura 1). Maior número de folhas foi observado em meio Knudson e MS adicionados de $2 \mathrm{mg} \mathrm{dm}^{-3}$ de BAP e MS e Roubelakis adicionados de $4 \mathrm{mg}$ $\mathrm{dm}^{-3}$ de BAP. Verificou-se menor número de folhas em meio Knudson adicionado de $4 \mathrm{mg} \mathrm{dm}^{-3}$ de
BAP. Resultados semelhantes foram obtidos por Oliveira (1994), trabalhando com crisântemo cultivado em meio MS, que observou queda no número com aumento das concentrações de BAP. Isto pode ser atribuído ao fato do BAP estimular a formação de maior número de brotos, porém, de tamanho reduzido, apresentando menor número de segmentos nodais e folhas.

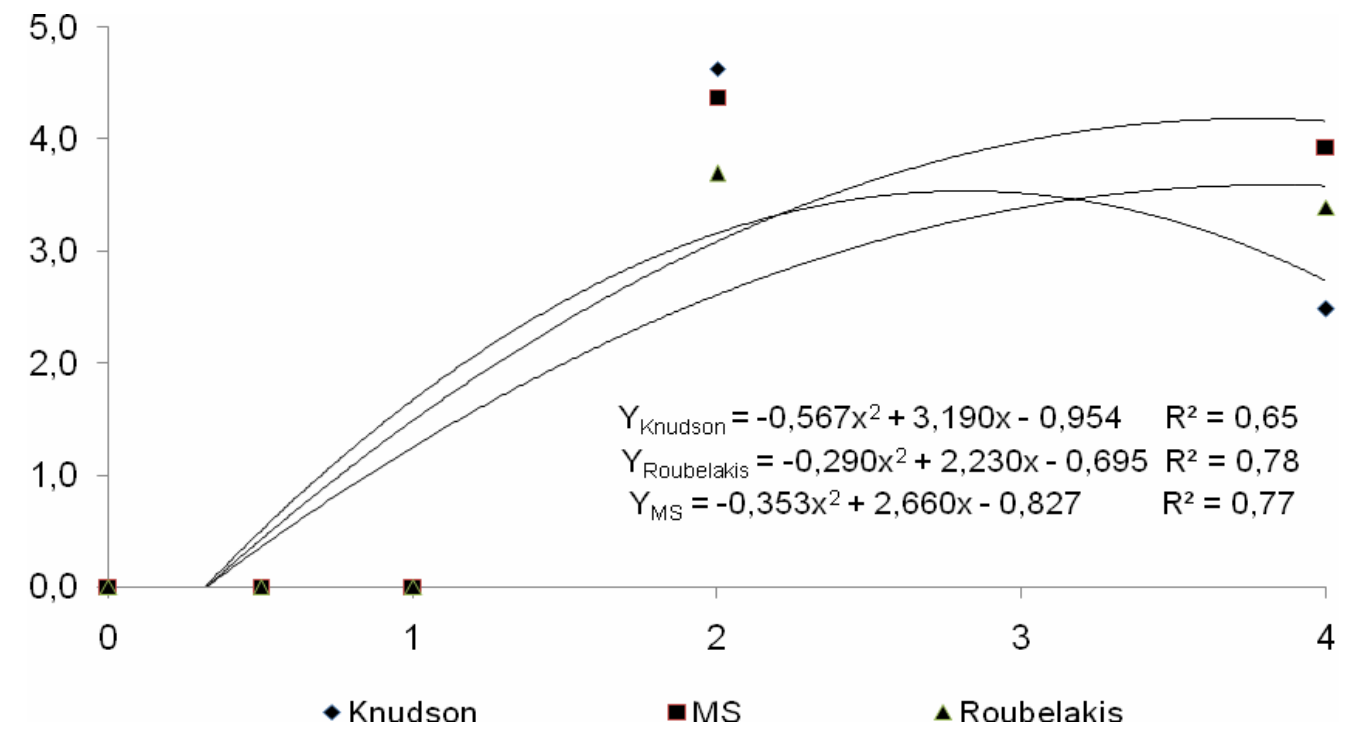

FIGURA 1 - Número de folhas de amoreira-preta cv. Brazos, em diferentes meios de cultura, adicionados de concentrações de BAP (ácido 6-benzilaminopurina). UFLA, Lavras, MG, 2008.

Através da análise de variância observouse que, o número de brotos da cv. Brazos foi estimulado pelo tipo de meio de cultivo e pela concentração de BAP separadamente (Tabelas 1 e 3). Em meio de cultivo MS verificou-se maior número de brotos. Em trabalho com café 'Catuai', objetivando determinar o efeito de diferentes proporções dos sais inorgânicos e componentes orgânicos do meio MS, Forni \& Pasqual (1996) observaram que o aumento dos níveis de MS proporcionou maior número de brotos, de folhas e peso da matéria seca. Com incremento nas concentrações de BAP, foi observado aumento de forma quadrática no número de brotos de amoreira-preta até $2 \mathrm{mg} \mathrm{dm}^{-3}$ de BAP. Após essa concentração, verificou-se um decréscimo nesses valores, devido ao fato da citocinina em altas concentrações ser tóxica às culturas in vitro.
Maior comprimento da parte aérea foi observado nos diversos meios de cultivo associados as cinco concentrações do regulador estudadas (Figura 2). Verificou-se maior alongamento dos brotos em meio Knudson, na ausência de BAP (Tabela 1). Menores alturas de brotações de amoreira-preta foram observadas em meio Knudson adicionado de altas concentrações da citocinina ( $1 \mathrm{mg} \mathrm{dm}^{-3}$ de BAP). Estes resultados concordam com a maioria dos autores que afirmam que este regulador de crescimento não é responsável pelo alongamento de brotos (Paiva et al., 1997). Leshem et al. (1988) mencionam ser tóxico o uso da citocinina em níveis elevados, caracterizando-se principalmente, pelo enrosetamento e falta de alongamento das culturas. 
VILLA, F. et al. Meio de cultura e reguladores...

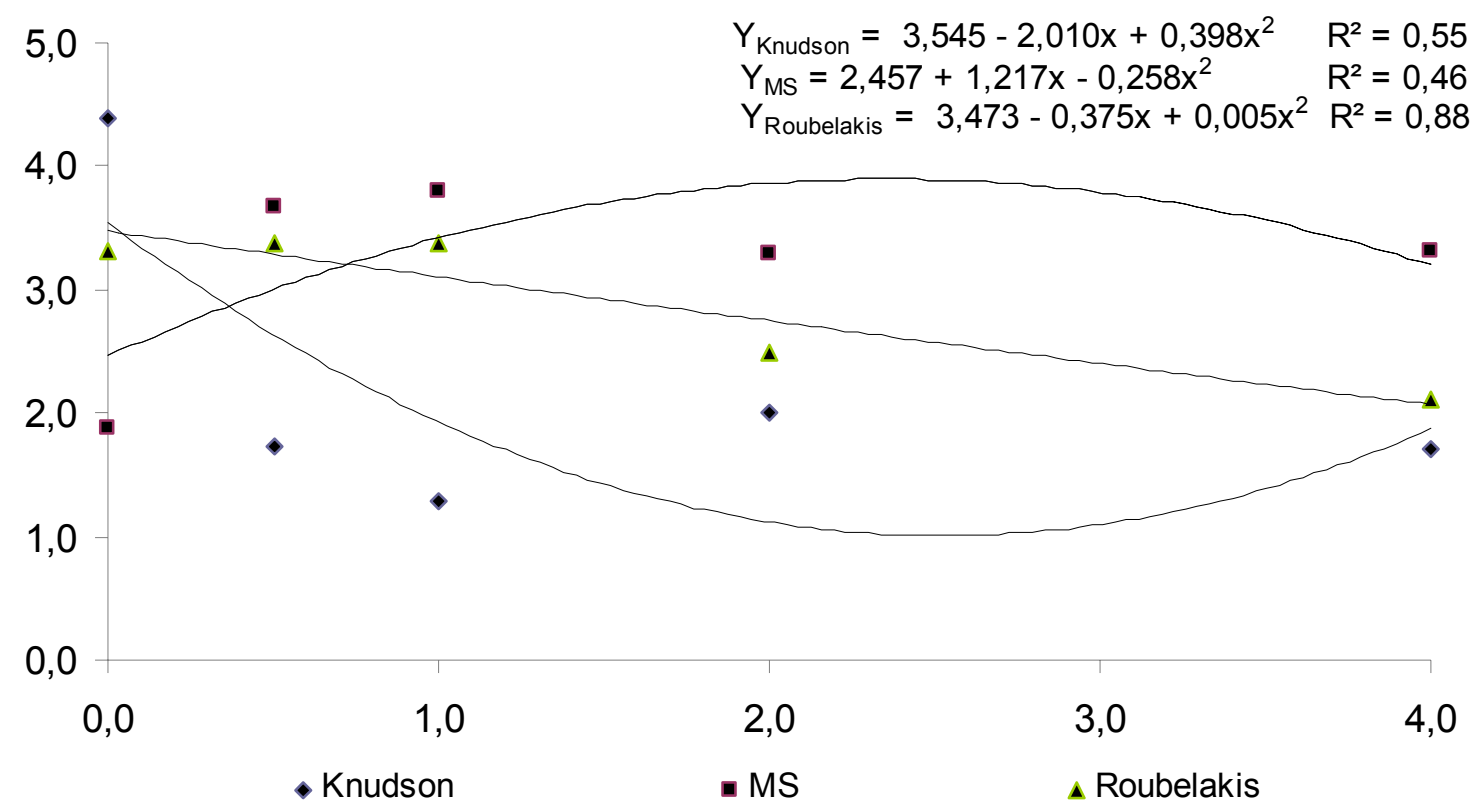

FIGURA 2 - Comprimento da parte aérea $(\mathrm{cm})$ de amoreira-preta cv. Brazos, em diferentes meios de cultura, adicionados de concentrações de BAP (ácido 6-benzilaminopurina). UFLA, Lavras, MG, 2008.

Verificou-se interação significativa para número (Figura 3) e comprimento das raízes em relação ao meio de cultivo e as concentrações de 0,$5 ; 1 ; 2$ e $4 \mathrm{mg} \mathrm{dm}^{-3}$ de BAP. Trabalhando com adição de $0,5-2 \mathrm{mg} \mathrm{dm}^{-3}$ de BAP no meio de cultura Roubelakis e MS, obtiveram-se maior número e comprimento de raízes. Em estudos com amoreira-preta, autores verificaram que o meio de cultura MS se sobressaiu na sua micropropagação
(Erig et al., 2002). O crescimento de plantas, órgãos, tecidos e células in vitro depende do desenvolvimento de meios de cultura otimizados para a perfeita interação de componentes essenciais como fontes de carbono e nutrientes minerais. Os fatores que limitam esse crescimento in vitro são similares àqueles que limitam in vivo (Wu et al., 2009).

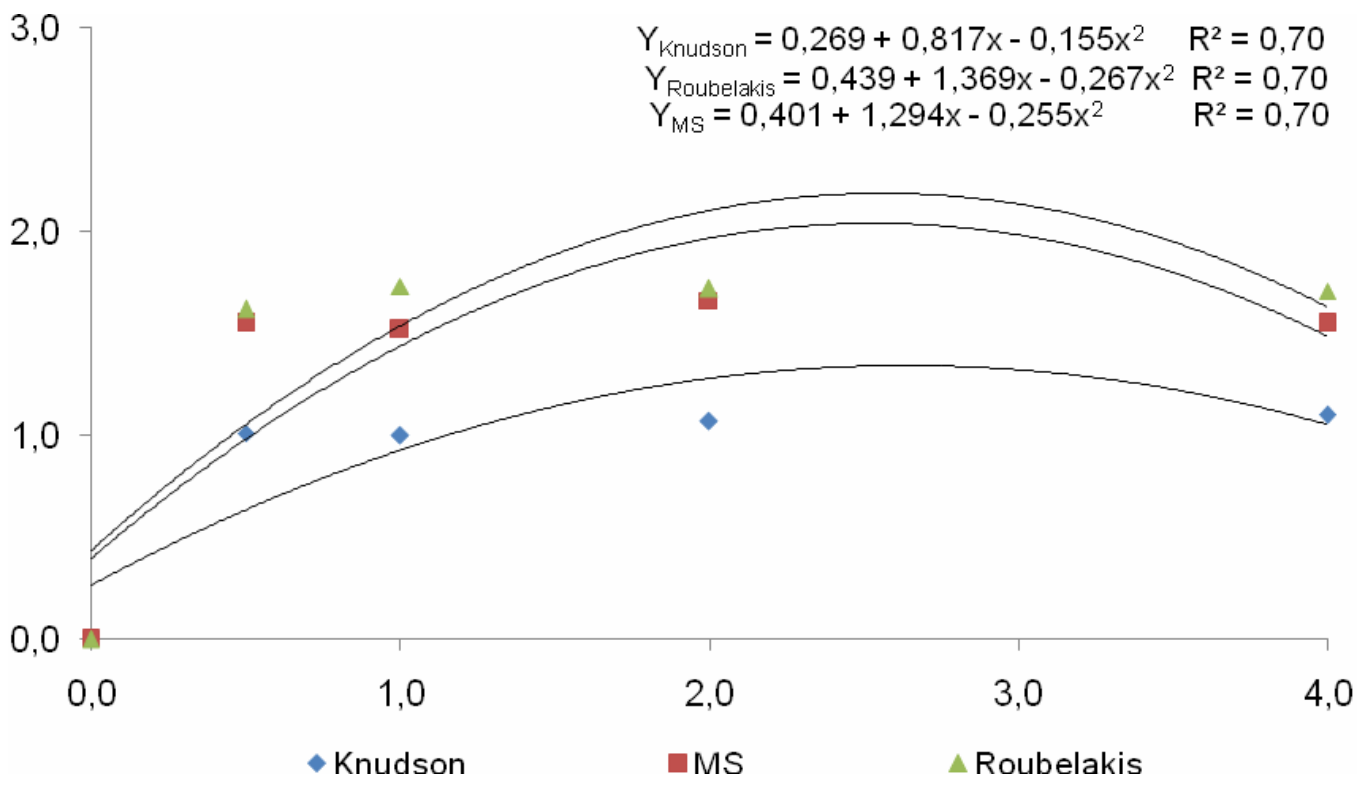

FIGURA 3 - Número de raízes de amoreira-preta cv. Brazos, em diferentes meios de cultura, adicionados de concentrações de BAP (ácido 6-benzilaminopurina). UFLA, Lavras, MG, 2008. 
VILLA, F. et al. Meio de cultura e reguladores...

A massa fresca da parte aérea foi estimulado pela utilização do meio de cultura. Melhores resultados foram obtidos em meio MS Com um aumento significativo da massa da matéria fresca no decorrer do tempo, o potencial osmótico do meio foi maior. Conseqüentemente, as plantas nesse meio conseguiram absorver mais água para os seus tecidos e, portanto, tiveram maior massa da matéria fresca.

A massa fresca de calos na base dos explantes de amoreira-preta foi influenciada pelos tipos de meio empregados e concentrações da citocinina (Figura 4). Maior peso de calos foi observado em meio MS associado a $2-4 \mathrm{mg} \mathrm{dm}^{-3}$ de BAP e em meio Roubelakis associado a 0,5-1 $\mathrm{mg} \mathrm{dm}^{-3}$. A formação de calos não é desejada na micropropagação da amoreira-preta (Leitzke et al., 2009). Provavelmente os meios descritos acima não sejam adequados para multiplicação in vitro de explantes da cv. Brazos. Em contrapartida, no meio de cultura Knudson houve menor formação de calos na base dos explantes e conseqüentemente, melhor desempenho dessas brotações e melhor enraizamento in vitro.

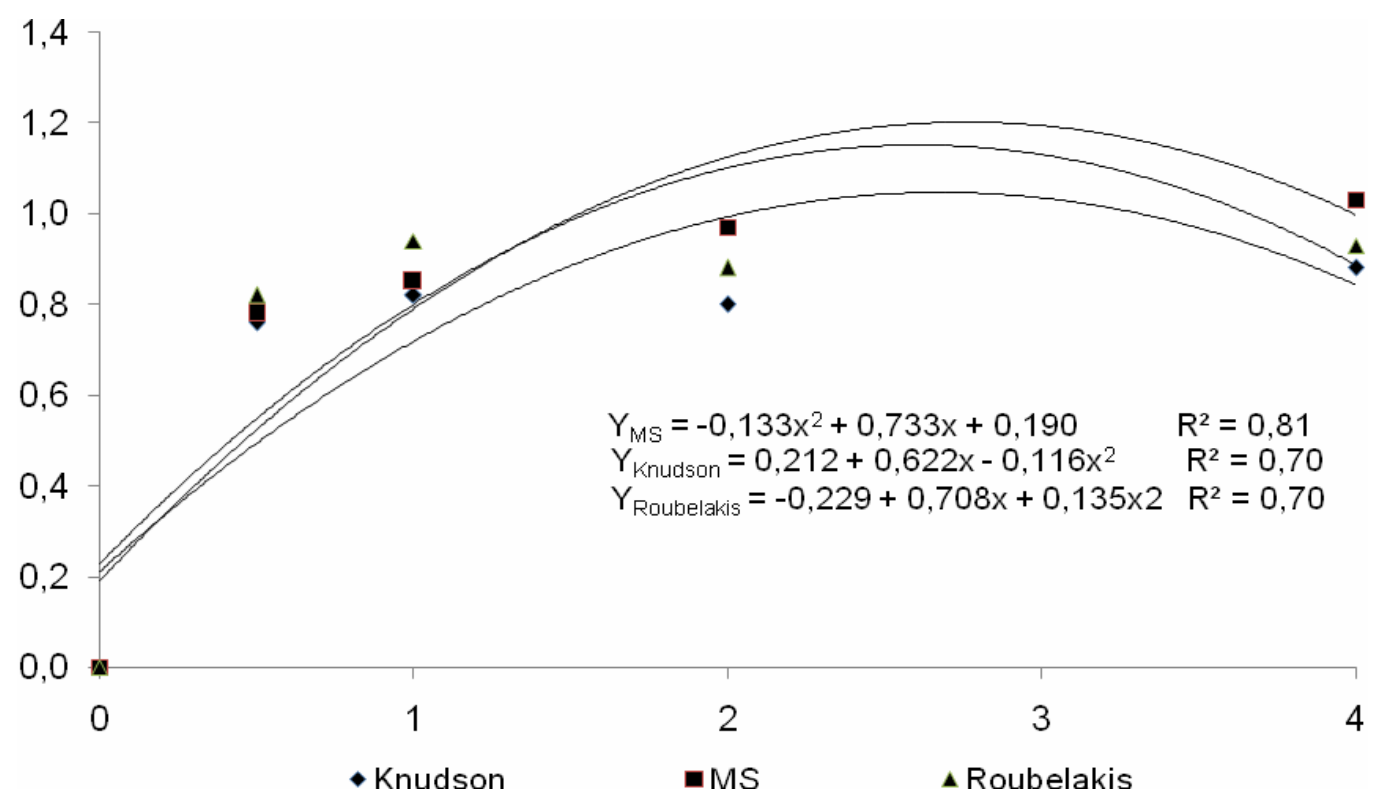

FIGURA 4 - Massa fresca da parte aérea ( $\mathrm{g}$ ) de amoreira-preta cv. Brazos, em diferentes meios de cultura, adicionados de concentrações de BAP (ácido 6-benzilaminopurina). UFLA, Lavras, MG, 2008.

\section{Experimento 2}

Verificou-se interação significativa para as variáveis analisadas em todas concentrações de AIB e meios de cultura empregados no estudo com a cv. Tupy. Nas Tabelas 4, 5, 6, observam-se os dados obtidos na avaliação feita 70 dias após a inoculação, relacionando-se o comprimento da parte aérea e das raízes de amoreira-preta cv. Tupy com os respectivos meios de cultura e concentrações de BAP e AIB.

TABELA 4 - Comprimento da parte aérea $(\mathrm{cm})$ de amoreira-preta cv. Tupy cultivada em diferentes meios de cultura, adicionados de concentrações de AIB (ácido indolbutírico). UFLA, Lavras, MG, 2008.

\begin{tabular}{lccccc}
\hline \multicolumn{5}{c}{ AIB $\left(\mathrm{mg} \mathrm{dm}^{-3}\right)$} \\
\hline Meios de cultura & 0 & 0,125 & 0,25 & 0,5 & 1,0 \\
\hline MS & $1,34 \mathrm{~b}^{*}$ & $1,47 \mathrm{~b}$ & $1,38 \mathrm{~b}$ & $1,47 \mathrm{~b}$ & $1,72 \mathrm{a}$ \\
Knudson & $1,31 \mathrm{~b}$ & $1,05 \mathrm{c}$ & $1,16 \mathrm{c}$ & $1,36 \mathrm{~b}$ & $1,49 \mathrm{~b}$ \\
Roubelakis & $1,07 \mathrm{c}$ & $1,20 \mathrm{c}$ & $1,45 \mathrm{~b}$ & $1,61 \mathrm{~b}$ & $1,56 \mathrm{~b}$ \\
NN & $1,89 \mathrm{a}$ & $1,84 \mathrm{a}$ & $1,72 \mathrm{a}$ & $1,90 \mathrm{a}$ & $1,90 \mathrm{a}$ \\
\hline
\end{tabular}

*Médias seguidas por letras minúsculas distintas diferem entre si na linha, ao nível de $5 \%$ de probabilidade pelo teste de Scott-Knott. 
VILLA, F. et al. Meio de cultura e reguladores...

TABELA 5 - Comprimento de raízes $(\mathrm{cm})$ de amoreira-preta cv. Tupy cultivada em diferentes meios de cultura, adicionados de concentrações de AIB (ácido indolbutírico). UFLA, Lavras, MG, 2008.

\begin{tabular}{lccccc}
\hline \multicolumn{5}{c}{ AIB $\left(\mathrm{mg} \mathrm{dm}^{-3}\right)$} \\
\hline Meios de cultura & 0 & 0,125 & 0,25 & 0,5 & 1,0 \\
\hline MS & $1,28 \mathrm{a}^{*}$ & $0,86 \mathrm{~b}$ & $1,51 \mathrm{a}$ & $1,47 \mathrm{a}$ & $1,33 \mathrm{a}$ \\
Knudson & $1,61 \mathrm{a}$ & $1,49 \mathrm{a}$ & $0,78 \mathrm{~b}$ & $1,28 \mathrm{a}$ & $1,31 \mathrm{a}$ \\
Roubelakis & $0,86 \mathrm{~b}$ & $1,33 \mathrm{a}$ & $0,86 \mathrm{~b}$ & $0,84 \mathrm{~b}$ & $0,78 \mathrm{~b}$ \\
NN & $1,27 \mathrm{a}$ & $1,18 \mathrm{a}$ & $1,36 \mathrm{a}$ & $1,43 \mathrm{a}$ & $1,43 \mathrm{a}$ \\
\hline
\end{tabular}

*Médias seguidas por letras minúsculas distintas diferem entre si na linha, ao nível de $5 \%$ de probabilidade pelo teste de Scott-Knott.

TABELA 6 - Comprimento de raízes $(\mathrm{cm})$ de amoreira-preta cv. Brazos cultivada em diferentes meios de cultura, adicionados de concentrações de BAP (ácido 6-benzilaminopurina). UFLA, Lavras, MG, 2008.

\begin{tabular}{|c|c|c|c|c|c|}
\hline \multirow[b]{2}{*}{ Meios de cultura } & \multicolumn{5}{|c|}{$\operatorname{BAP}\left(\mathrm{mg} \mathrm{dm}^{-3}\right)$} \\
\hline & 0 & 0,125 & 0,25 & 0,5 & 1,0 \\
\hline MS & 0 & 0,5 & 1,0 & 2,0 & 4,0 \\
\hline Knudson & -- & $1,60 \mathrm{a}$ & $1,62 \mathrm{a}$ & $1,58 \mathrm{a}$ & $1,57 \mathrm{a}$ \\
\hline Roubelakis & --- & $0,92 b$ & $0,71 \mathrm{~b}$ & $0,97 \mathrm{~b}$ & $0,84 \mathrm{~b}$ \\
\hline
\end{tabular}

*Médias seguidas por letras minúsculas distintas diferem entre si na linha, ao nível de $5 \%$ de probabilidade pelo teste de Scott-Knott.

Maior comprimento da parte aérea (Figura 5) foi verificado em meio NN adicionado ou não de AIB (Tabela 4), sugerindo que a concentração desse meio em relação aos outros testados é ideal para o crescimento e desenvolvimento da parte aérea de plantas de amoreira-preta cv. Tupy. O efeito da composição dos meios de cultura sobre o desenvolvimento de frutíferas já foi constatado também por diversos autores (RoubelakisAngelakis \& Zivanovitc, 1991; Nali et al., 2005).

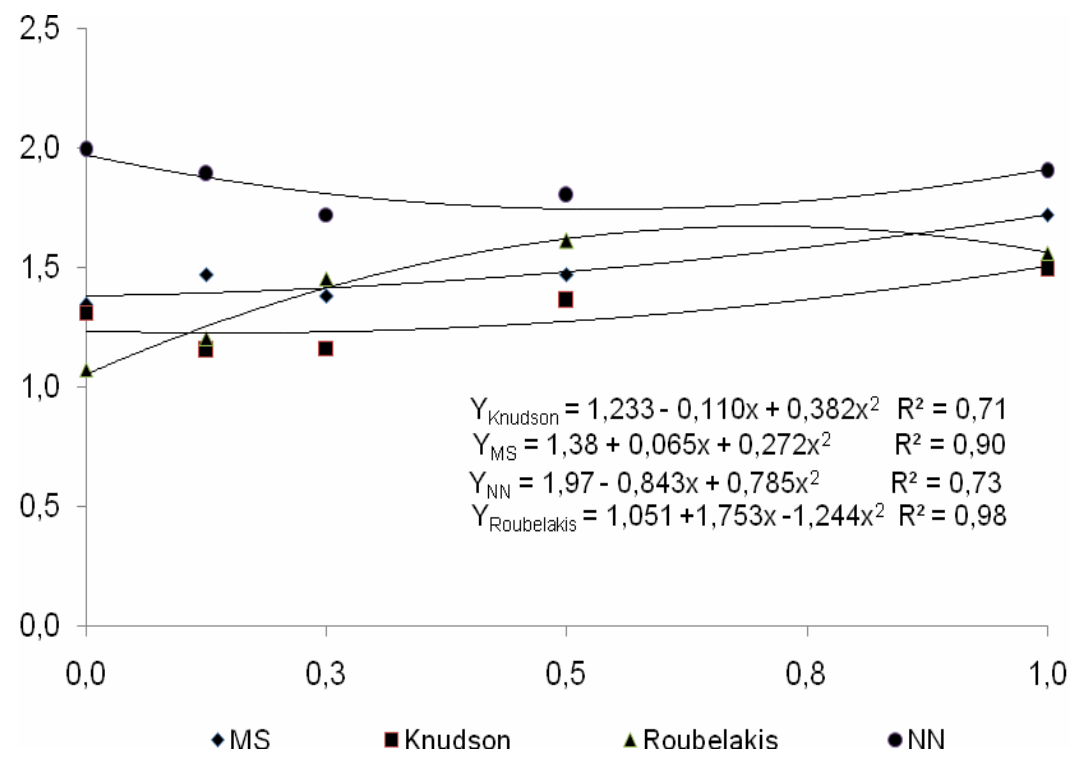

FIGURA 5 - Comprimento da parte aérea $(\mathrm{cm})$ de amoreira-preta cv. Tupy, em diferentes meios de cultura, adicionados de concentrações de AIB (ácido indolbutírico). UFLA, Lavras, MG, 2008. 
VILLA, F. et al. Meio de cultura e reguladores...

Os resultados aqui apresentados para as duas cultivares corroboram Erig et al. (2002), que afirmaram que, nas concentrações de 0 e $1 \mu \mathrm{mol}$ $\mathrm{dm}^{-3}$ de AIB, o aumento nos níveis de BAP resultou na diminuição do comprimento médio das brotações in vitro da cv. Tupy. Elevados níveis de citocinina no meio de cultura podem ser tóxicos à cultura, caracterizada pelo demasiado enrosetamento e falta de alongamento das culturas (Leshem et al., 1988).
Foi observada a formação do sistema radicular das plantas em todos os meios empregados, porém melhores resultados na ausência de AIB deu-se nos meios Knudson, NN e MS (Figura 6). Resultados semelhantes foram observados com a adição de $0,5 \mathrm{mg} \mathrm{dm}^{-3}$ do regulador. Com outras concentrações do fitohormônio, o meio de cultivo que se destacou foi o MS.

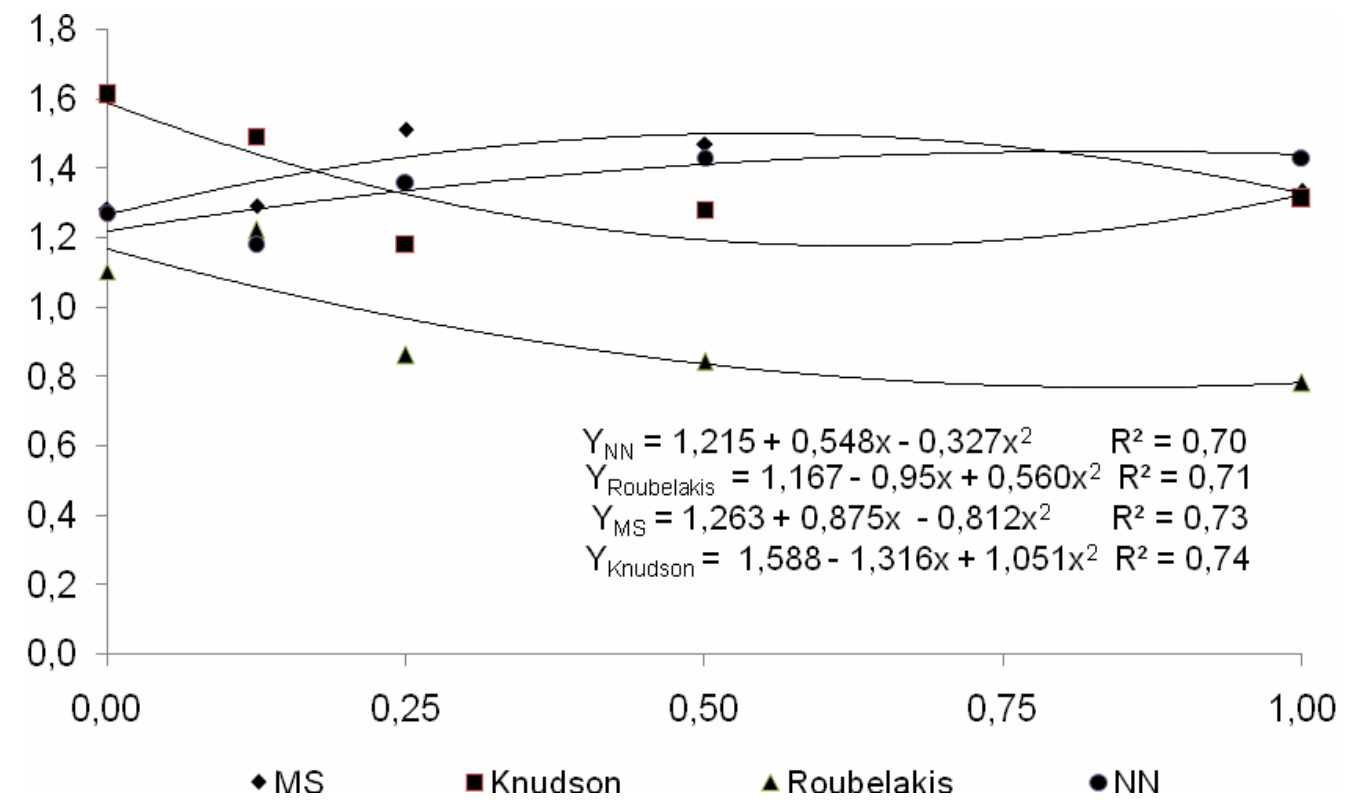

FIGURA 6 - Comprimento de raízes $(\mathrm{cm})$ de amoreira-preta cv. Tupy, em diferentes meios de cultura, adicionados de concentrações de AIB (ácido indolbutírico). UFLA, Lavras, MG, 2008.

Mesmo na ausência de AIB observou-se que os meios de cultura tiveram papel importante no crescimento do sistema radicular, sendo que os meios MS, Knudson e NN não diferem estatisticamente (Tabela 5).

Erig et al. (2002) obtiveram melhor enraizamento de amoreira-preta adicionando 0,1 $\mathrm{mg} \mathrm{dm^{-3 }}$ de ácido indolbutírico (AIB) ao meio MS, promovendo a formação de mudas bem desenvolvidas. Isto, provavelmente, se deve ao fato de se utilizarem diferentes genótipos, os quais respondem melhor à adição de auxina ao meio de cultivo. Provavelmente, a cultivar Tupy apresente quantidade de auxina endógena suficiente para estimular o enraizamento, não respondendo, portanto, à adição de auxina exógena ( $\mathrm{Wu}$ et al., 2009).

Diversas espécies, principalmente as herbáceas, enraízam com níveis muito reduzidos de auxina ou em meio básico sem substâncias de crescimento (Vejsadová, 2008). Nesse caso, as partes aéreas em rápido crescimento são fontes de intensa produção de auxina, a qual é translocada para a base, estimulando a rizogênese.

Para a massa fresca da parte aérea, os meios de cultura utilizados na micropropagação de amoreira-preta não diferiram entre si estatisticamente com a adição de $0,125 \mathrm{mg} \mathrm{dm}^{-3}$ de AIB. Na ausência desse regulador, os meios que se destacaram foram o NN, MS e Knudson. Com a adição de 0,25 e $0,5 \mathrm{mg} \mathrm{dm}^{-3}$ de AIB, melhores resultados no peso fresco da parte aérea foram obtidos em meios MS, NN e Roubelakis.

Menores valores para essa variável foram obtidos em meio Knudson com 1,0 mg dm ${ }^{-3}$ de AIB. Esse meio, por ser mais diluído que os meios empregados na multiplicação in vitro de amoreirapreta, fornece menor quantidade de nutrientes essenciais ao desenvolvimento dos explantes, mesmo com a adição do fitorregulador.

\section{CONCLUSÕES}

A utilização de $2 \mathrm{mg} \mathrm{dm}^{-3}$ de BAP promove maior número de brotos de amoreira-preta cultivar Brazos. Melhores resultados para biomassa da 
parte aérea de 'Brazos' foram observados em meio MS. Maior número e comprimento de raízes foram verificados nos meios MS e Roubelakis adicionados de $0,5 \mathrm{mg} \mathrm{dm}^{-3}$ de BAP. Menor formação de calos de 'Brazos' ocorreu em meio de cultura Knudson.

Maior comprimento da parte aérea e número de raízes de 'Tupy' foram obtidos nos meios NN e
VILLA, F. et al. Meio de cultura e reguladores..

MS, com a adição de 0,5-1 $\mathrm{mg} \mathrm{dm}^{-3}$ de AIB. Para o sistema radicular de 'Tupy', os meios que se destacaram foram o Knudson, MS e NN, sem a presença da auxina. Com $1 \mathrm{mg} \mathrm{dm}^{-3}$ de AIB adicionada em meio Roubelakis obteve-se maior biomassa da parte aérea de 'Tupy'.

\section{REFERÊNCIAS}

1. ANTUNES, L. E. C. Amora-preta: nova opção de cultivo no Brasil. Ciência Rural, v. 32, n. 1, p. 151-158, 2002.

2. ANTUNES, L. E. C. et al. Blossom and ripening periods of blackberry varieties in Brazil. Journal of the American Pomological Society, v. 54, n. 4, p. 164-168, 2000.

3. ERIG, A. C.; DE ROSSI, A.; FORTES, G. R. L. 6-benzilaminopurina e ácido indolbutírico na multiplicação in vitro da amoreira-preta (Rubus idaeus L.), cv. Tupy. Ciência Rural, v. 32, n. 5, p. 765-770, 2002.

4. FERREIRA, D. F. Análises estatísticas por meio do Sisvar para Windows versão 4.0. In: REUNIÃO ANUAL DA REGIÃO BRASILEIRA DA SOCIEDADE INTERNACIONAL DE BIOMETRIA, 45., 2000, São Carlos. Anais... São Carlos: UFSCar. 2000. p. 255-258.

5. FORNI, R. C.; PASQUAL, M. Influência da citocinina BAP e concentrações dos componentes do meio "MS" na micropropagação do café 'Catuaí'. Ciência e Agrotecnologia, v. 20, n. 4, p. 468-474, 1996.

6. GEORGE, E. F.; SHERRINGTON, P. D. Plant propagation by tissue culture. 1. ed. Eversley: Exegetics, 1984. $709 \mathrm{p}$.

7. GRATTAPAGLIA, D.; MACHADO, M. A. Micropropagação. In: TORRES, A. C. et al. (Ed.). Cultura de tecidos e transformação genética de plantas. 2. ed. Brasília: EMBRAPA/CNPH, 2004. p. 183-260.

8. GRIMALDI, F. et al. Enraizamento in vitro de frutíferas da família Rosaceae. Revista de Ciências Agroveterinárias, v. 7, n. 2, p. 160-168, 2008.

9. KNUDSON, L. A new nutrient solution for the germination of orchid seed. American Orchid Society Bulletin, v. 14, n. 1, p. 214-217, 1946.

10. LEITZKE, L. N.; DAMIANI, C. R.; SCHUCH, M. W. Meios de cultura, concentração de AIB e tempo de cultivo no enraizamento in vitro de amoreira-preta e framboeseira. Revista Brasileira de Fruticultura, v. 31, n. 2, p. 582-587, 2009.

11. LESHEM, B.; WERKER, E.; SHALEV, D. P. The effect of cytokinins on vitrification in melon and carnation. Annals of Botany, v. 62, n. 3, p. 271-276, 1988.

12. MURASHIGE, T.; SKOOG, F. A revised medium for rapid growth and bio assays with tobacco tissue cultures. Physiologia Plantarum, v. 15, n. 3, p. 473-497, 1962.

13. NALI, L. R.; ALMEIDA, W. A. B.; MELO, N. F. Propagação in vitro de videiras. Magistra, v. 17, n. 2, p. 96-100, 2005.

14. NITSCH, J. P.; NITSCH, C. Haploids plants from pollen grains. Science, v. 163, n. 3862, p. 85-87, 1969.

15. OLIVEIRA, P. D. Propagação in vitro de crisântemo (Dendranthema grandiflora Tzlev.) cv. Orange Reagen. 1994. 116 p. Dissertação (Mestrado em Fitotecnia) - Escola Superior de Agricultura de Lavras, Lavras, 1994.

16. PAIVA, P. D. O. et al. Propagação in vitro de gloxínia. Revista Brasileira de Horticultura Ornamental, v. 3, n. 2, p. 29-41, 1997.

17. ROUBELAKIS-ANGELAKIS, K. A.; ZIVANOVITC, S. B. A new culture medium for in vitro rhizogenesis of grapevine (Vitis spp.) genotypes. HortScience, v. 26, n. 12, p. 1551-1553, 1991.

18. VEJSADOVÁ, H. Growth regulator effect on in vitro regeneration of rhododendron cultivars. Horticultural Science, v. 35, n. 2, p. 90-94, 2008.

19. VILLA, F. et al. Micropropagação da amoreira-preta (Rubus spp.) e efeito de substratos na aclimatização de plântulas. Acta Scientiarum Agronomy, v. 28, n. 1, p. 47-53, 2006.

20. VILLA, F. et al. Crescimento in vitro de amoreira-preta: efeitos de reguladores de crescimento e da cultivar. Ciência e Agrotecnologia, v. 32, n. 6, p. 1754-1759, 2008.

21. WU, J. H. et al. Factors affecting the efficiency of micropropagation from lateral buds and shoot tips of Rubus. Planto Cell, Tissue and Organ Culture, v. 99, n. 1, p. 17-25, 2009. 
